\title{
Landscape Design of the University New Campuses Based on Regional Characteristics-Using Fengxian New Campus of East China University of Science and Technology as an Example
}

\author{
Lu Feng ${ }^{1, *}$ \\ ${ }^{1} \mathrm{PhD}$, Lecturer, East China University of Science and Technology, China
}

\begin{abstract}
In the past 40 years of reform and opening up, China's higher education and campus construction have made historic achievements. This paper reviews the history of this process in the 40 years, while summarises the characteristics and requirements of current new campus by comparing multiple new campuses in china. The paper uses East China University of Science and Technology as an example, to analysis the problems of neglecting the regional characteristics and far-fetched embodiment of university culture. This paper puts forward the concept of using regional characteristics to strengthen university culture, and unfolds in natural features, evolution process and farming habits within two specific plots.
\end{abstract}

\section{Introduction}

Since the founding of new China, especially in the 40 years of reform and opening up, China's higher education has undergone earth-shaking changes. In 1977, the resumption of college entrance examination unveiled the prelude of this transformation. In the 1990s, the strategy of invigorating the country through science, technology and education has greatly promoted the scale and quality of higher education. And in 1999, the big scale enlargement was the turning point. In 1998, the number of enrolled students in ordinary colleges and universities nationwide was 1.084 million. By 1999, it had reached 1.597 million, an increase of $47.3 \%$ over the previous year. Between 1999 and 2005, the rate of enlargement maintained at around $20 \%$ per year. As the end of 2017, the enrolment had sky-rocked to 47.79 million, with a gross enrolment rate of $45.7 \%$, ranking No.1 in the world [1].

During the same time, the enlargement of the higher education has directly leaded to the expansion of the campus construction. According to the National Statistical Report on Education Development 1998 to 2017, the number of higher education instittution had increased from 1022 to 2631(Fig 1). The overall floorage of campus building had increased from 15400 ha to 95400 ha, which is 6 times of the original. As the old campuses are uslally near the downtown and become over crowed, a lot of universities search to build new campuses.

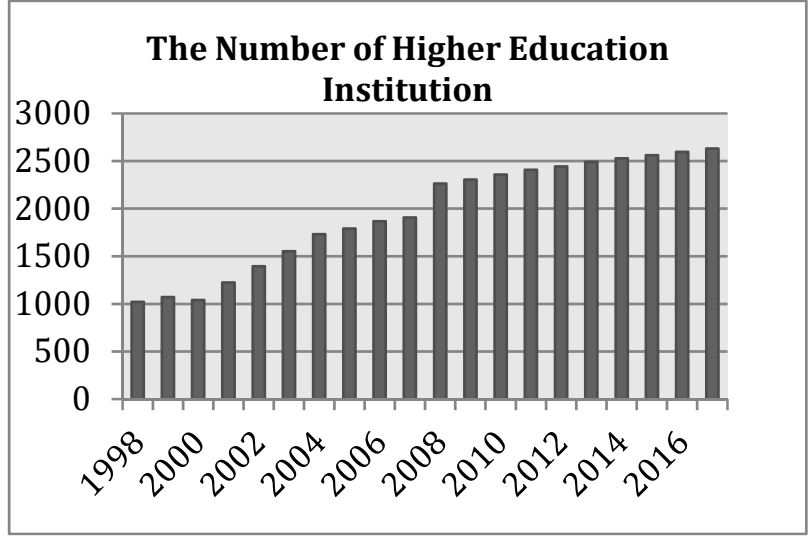

Fig. 1. The number of higher education institution

\section{The challenges of the new campuses in the new area}

The construction of a large number of new campuses has filled the need for a rapidly expanding education scale and created new opportunities for the higher education. However, many problems also surfaced in the construction of such a fast pace. Among them, the most prominent problem in the campus landscape is all of the same pattern, neither reflecting the characteristics of the university nor the region. This is mainly caused by the following reasons:

\subsection{Regional and spatial restriction}

Due to the price of land and the overall planning of the city, many new campuses are located on the edge of the city or in the satellite city. Although this is costing saving and can drive the development of the surrounding

\footnotetext{
* Corresponding author: fenglubjfu@163.com
} 
area, it also brings many restrictions to the new campus itself. Because it is far away from the main urban area, the supporting facilities are deficient, the cultural atmosphere is difficult to keep up, and the life of teachers and students is relatively monotonous. So the new campus is easy to become a cultural " isolated island". The historical and cultural traditions of a place have a strong penetration of college campus culture[2]. Relatively, the external environment of the new campus lacks cultural and historical precipitation, and it is also difficult to nourish a unique campus culture.

\subsection{One-sided display of new campus culture}

Some universities have a long history and distinctive features. But for the new campus, the culture is mostly displayed in the ways of university motto, alumni monuments, sculptures, cultural walls, etc., and is presented in the form of textual narratives and mostly representational. This is also the most common display way on university campuses across the country, and it is difficult to highlight campus features. The author surveyed the new campuses of several famous universities in Shanghai, which all located at the edge of urban area or satellite cities. It can be seen that although the geographical location are different, the campus style is similar (Table 1). In addition, some universities' culture have not been prominent due to repeated reorganizations, renaming, etc. In this situation, it is too weak to reflect the campus culture and characteristics through the university badge, university motto, and famous alumni. It is necessary to further explore the characteristics of the university and even reshape it.

Table 1. Comparison between 3 new campuses in Shanghai

\begin{tabular}{|c|c|c|c|c|}
\hline University & $\begin{array}{c}\text { Locatio } \\
\text { n }\end{array}$ & $\begin{array}{c}\text { Distance to } \\
\text { People's } \\
\text { Square } \\
\end{array}$ & $\begin{array}{l}\text { Building } \\
\text { style/ colour }\end{array}$ & $\begin{array}{c}\text { Main tree } \\
\text { species }\end{array}$ \\
\hline $\begin{array}{c}\text { Tongji } \\
\text { University }\end{array}$ & $\begin{array}{l}\text { Jiading } \\
\text { district }\end{array}$ & $30 \mathrm{~km}$ & $\begin{array}{l}\text { modern/ red } \\
\text { and white }\end{array}$ & $\begin{array}{l}\text { Camphor, } \\
\text { Metasequ } \\
\text { oia, Plane } \\
\text { tree, Etc. }\end{array}$ \\
\hline $\begin{array}{l}\text { Shanghai } \\
\text { Jiaotong } \\
\text { Univeristy }\end{array}$ & $\begin{array}{c}\text { Minhan } \\
\mathrm{g} \\
\text { district }\end{array}$ & $32 \mathrm{~km}$ & $\begin{array}{l}\text { modern/ red } \\
\text { and white }\end{array}$ & $\begin{array}{l}\text { Camphor, } \\
\text { Koelreuter } \\
\text { ia } \\
\text { Paniculata } \\
\text {, Plane } \\
\text { tree, Etc. }\end{array}$ \\
\hline $\begin{array}{l}\text { East China } \\
\text { University } \\
\text { of Science } \\
\text { and } \\
\text { Technology }\end{array}$ & $\begin{array}{c}\text { Fengxia } \\
n \\
\text { district }\end{array}$ & $55 \mathrm{~km}$ & $\begin{array}{l}\text { modern/ red } \\
\text { and white }\end{array}$ & $\begin{array}{l}\text { Camphor, } \\
\text { Metasequ } \\
\text { oia, Plane } \\
\text { tree, Etc. }\end{array}$ \\
\hline
\end{tabular}

\subsection{Stick to the old campus culture and lack of innovative spirit}

The old campus has a relatively distinct cultural characteristic after decades or even hundreds of years of historical accumulation, so the construction of the new campus should echo to the old campus. However, some universities have invested heavily in simply copying the buildings and even the layout of the old campus, transplanting old trees or relocating school mottos. It is not only uneconomical and difficult to integrate with new campuses, but also the cultural heritage cannot be fully realized. Any kind of campus culture does not come from inheritance, and more of it is gradually formed in the development of university construction. Therefore, it is not necessary to deliberately copy the old culture. As long as it conforms to the school motto and the spirit, it can boldly rely on the local environment of the new campus to create. For example, Harvard's Tanner Fountain was designed and built in 1984. Compared with Harvard's nearly 400 -year history, this is undoubtedly a new thing, but now it is an important place for teachers and students to relax and become an important campus attraction. (Fig 2).

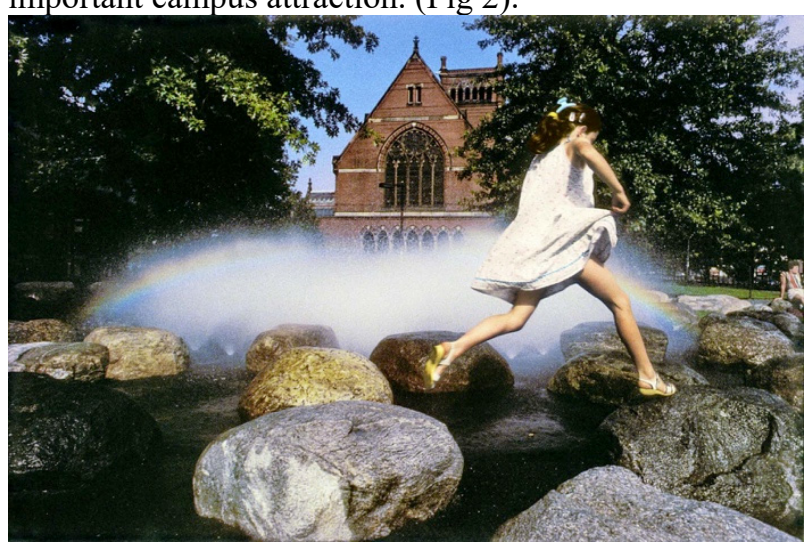

Fig. 2.Tanner fountain, source: http://www.pwpla.com

\section{The design strategies of new campuses based on regional characteristics in the new area}

In 2016, the Ministry of Education began to deploy world-class universities and world-class disciplines (referred to as "double world class") construction, which puts forward higher requirements for higher education in the new era, and pays more attention to quality improvement and cultural construction of colleges and universities. The report of the 19th National Congress also proposed the implementation of campus culture, addressed to promote cultural inheritance and innovation. The university campus is an important carrier of university culture. The construction of the new campus should be based on regional characteristics, which not only inherits the culture of the old campus but also highlights the characteristics of the new campus.

\subsection{Excavation and inheritance of regional characteristics}

As a subset of culture, regional culture is a unique cultural form produced by the combination of local 
geography, economic conditions and humanistic spirit in the process of cultural inheritance. Since the new campus has been separated from the old campus and most universities have chosen a relatively remote area, they should base on the regional characteristics, give the new campus a new culture, and through the excavation of regional characteristics to enrich the old culture.

Among them, the characteristics of natural geography are relatively easy to dig, and this is an opportunity for the new campus. Compared with the old campus, which is mostly in the flat area of the city center, the new campus may be close to farmland, mountains, lakes, tidal flats, etc., which is relatively a distinct location. Therefore, it should be retained and highlighted in the planning and design of the new campus to match the local planting, topography and materials. For example, the Xiangshan Campus of the China Academy of Art is also a relatively remote new campus. It does not re-enact the old campus, but instead adapts to local conditions. It introduces the local farmland and natural mountain scenery of Zhuantang Town into the campus, continuing the original and interesting nature of the site. Rape, sunflower, sorghum, corn and other native woodland plants such as chinese tallow tree, pterocarya stenoptera, and chinese elm form a unique campus landscape and even become one of the most popular attractions in Hangzhou (Fig 3).

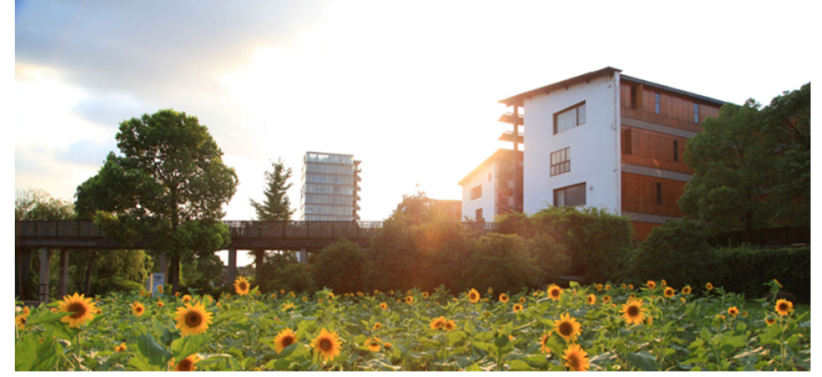

Fig. 3.Campus of the China Academy of Art, source: http://sjgm.caa.edu.cn

On the other hand, the excavation of regional humanistic characteristics is relatively difficult. To get rid of this predicament, we should use more open ideas instead of simply moving the surrounding folk customs to the campus. The new campus should break the regional and spatial restriction and open the "island of culture" to the periphery and become a "bridge of culture". The infiltration of activities inside and outside the school will truly enrich the campus culture and drives the development of the surroundings.

\subsection{The change and development of regional characteristics}

The inheritance of regional characteristics should not only focus on the excavation of history, but also the rapid development of modern society. Especially in the 40 years of reform and opening up, China has undergone earth-shaking changes. If the emphasis on regional characteristics is to restore the historical appearance, it is too shackled. In particular, many new campuses are located in the rapidly growing urban fringe area. With the rapid urbanization process, natural features are gradually weakening, and new regional features are being formed. The new campus should follow the trend of era and even lead the development trend of the region. Therefore, on the one hand, the new campus should be given the spirit of space on the basis of natural geography, and make new creations and changes to adapt to the needs of the new era. Only the history of being utilized is the history that has really been passed down. On the other hand, it is necessary to distinguish between new things and development trends, retaining and adapting to the long-term development value and prospects, and creating a new campus culture.

\section{Case study}

\subsection{Project overview}

The main campus of East China University of Science and Technology is located in Xuhui District, Shanghai. The university has established two new campuses: Fengxian Campus and Jinshan Campus. The Fengxian Campus is located at No. 999, Haisi Road, Haiwan Town, Fengxian District, Shanghai. It was opened in September 2007 and covers an area of 103 ha. It is two kilometers from the sea and 55 kilometers from the People's Square in downtown. It belongs to the subtropical monsoon climate and has a flat and open terrain. It is planned to build more than 600,000 square meters of various types of buildings, all of which will accommodate 20,000 students [3]. At present, the construction of Fengxian Campus has been basically completed. Like most new campuses, this campus has a modern architectural style, garden-type landscape, and campus characteristics are not obvious. However, in 2016, the university launched the campus cultural environment optimization and upgrading project of Xuhui Campus, and Fengxian Campus also promoted the campus culture through the transformation of several experimental plots.

\subsection{Transformation concept}

With the expansion of the higher education scale in the late $1990 \mathrm{~s}$, the $21 \mathrm{st}$ century was the golden age of the new campus construction, and these campuses have been basically completed. The large scale of new campuses construction will be more difficult to emerge in the new area, and the upgrading of these new campuses will be main mission that will be faced for a long time in the future. East China University of Science and Technology is also at the same stage. Because the architectural style has been determined, the campus structure is basically fixed. Starting from the landscape level, it is a more realistic and efficient method to shape the campus features through the gradual transformation of various plots. Among them, the geographical location of Fengxian Campus has caused inconvenience but also brought about the help of distinctive geographical features. 


\subsection{Plot design and regional characteristics}

\subsubsection{Reed garden and the inheritance of regional characteristics}

Haiwan Town is located at the forefront of the Yangtze River Delta. Reed is an important dominant vegetation in local tidal flats. Its ability to fix carbon, purify water and improve soil is much higher than that of garden trees and shrubs. Since 2000, most of the land on the coast has been transformed into enclosures. The wild reeds in the enclosure have been destroyed. The Fengxian campus was also developed from the original reed beach (Fig. 4). Today, the campus has been basically completed, leaving only a 1.2-hectare reed land in the southeast corner. This reed land is very valuable because it records the natural landscape and development history of Fengxian campus. Therefore, the author tried to retain the reed land, and intended to build it into a campus wetland integrating functions of recreation, science popularization and appreciation (Figure 5).

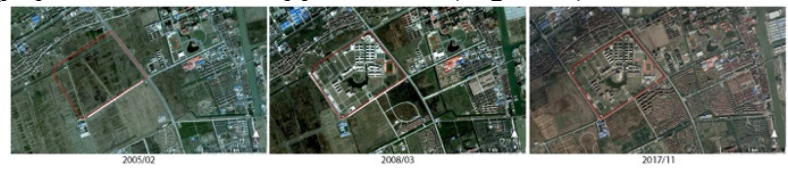

Fig. 4. Transition of Fengxian campus, source: google map

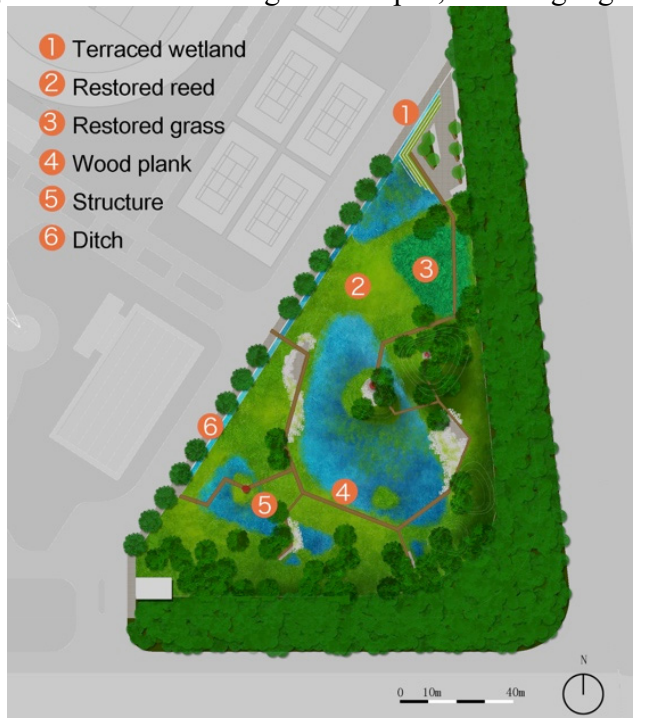

Fig. 5. Master plan, source: author

On the Fengtuo Highway not far from the campus, a seawall, called Huating Haitang, was built 300 years ago. It was built at the time to protect farmland and houses. Now because of the land reclamation, the seawall has been far away from the coast, and no longer plays a protective role, but it records the history of the symbiosis between the locals and the sea tide. Therefore, the building style of the seawall is also used in the design, but it has been given new functions. Using the same bluestone and same masonry method but transforming into a demonstrative terraced wetland., the relationship between Fengxian campus and the sea is shown from the perspective of modernity and science popularization (Fig. $6)$.

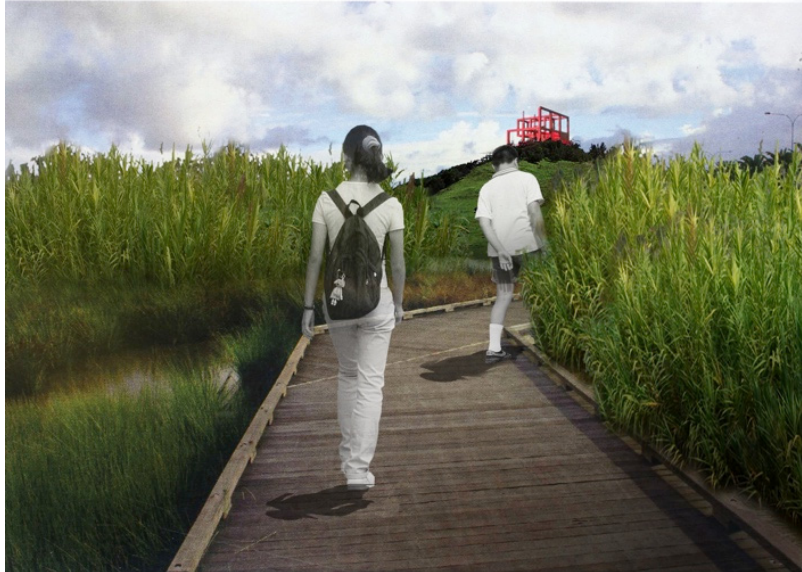

Fig. 6. Perspective, source: author

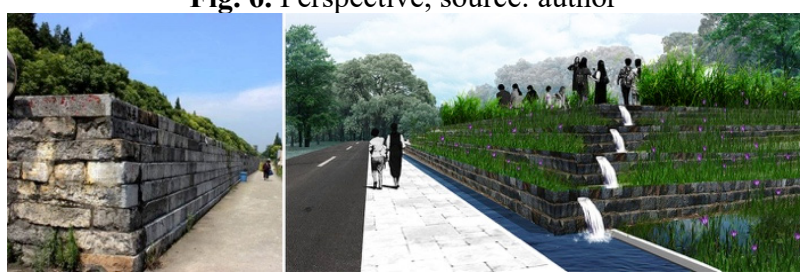

Fig. 7. Huating Haitang and terraced wetland, source: author

\subsubsection{Cole flower garden and the carrying forward of regional characteristics}

Compared with the other two university towns in Shanghai, Songjiang University town and Nanhui University town, the surrounding area of Fengxian University town is more agricultural. The farmland can be seen from the Fengxian campus. Among them, rapeseed is one of the main agricultural products in Fengxian District. In 2017, the output reached 1,000 tons. [4] In recent years, Fengxian Cole flower Festival has become a famous brand and has been held for eleven sessions. It is one of the three characteristics of Fengxian Agricultural Tourism. At present, the cole flower planting area is over 20,000 $\mathrm{mu}[5]$. It can be seen that cole flower has gradually become one of the characteristics of Fengxian in the new era and is a new development of regional characteristics.

There is an open space of about 1 hectare in the entrance of the new campus. The outside of the open space is the cole flower farmland planted by the farmers. In the renovation of the new campus, the author positioned the plot as a distinctive entrance landscape for people to enjoy. The earthwork on site, which is excavated from the construction of the nearby student dormitory, is shaped into three terrains with different heights. The cultivation of the cole flower forms a flame pattern, on the one hand, it is better adapted to the topography, and on the other hand, it forms a strong visual effect of the sparks (Fig.8). In the details, it breaks through the traditional ridge-type planting of cole flower, so that it is tangent with the lawn to form a contrast between the rough of the cole flower and the exquisite of the grass (Fig.9). The road is paved with gravels, which is cost-effective and easy to maintain(Fig.10). During the blossom season, the interior and exterior of the campus are golden, blurring the boundaries and introducing the new regional characteristics of Fengxian into the campus. 
The reconstructed plot has also become a popular hot spot, attracting many teachers and students and residents from and outside the school to take photos.

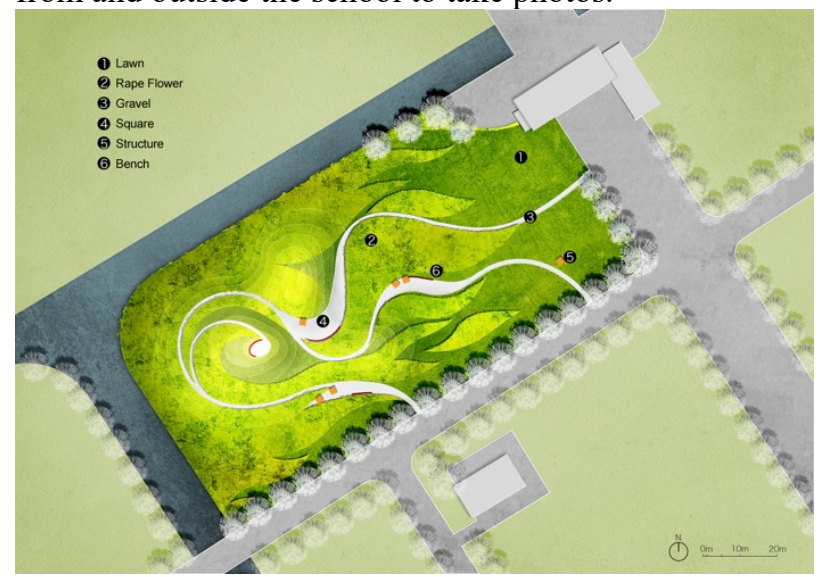

Fig. 8. Master plan, source: author

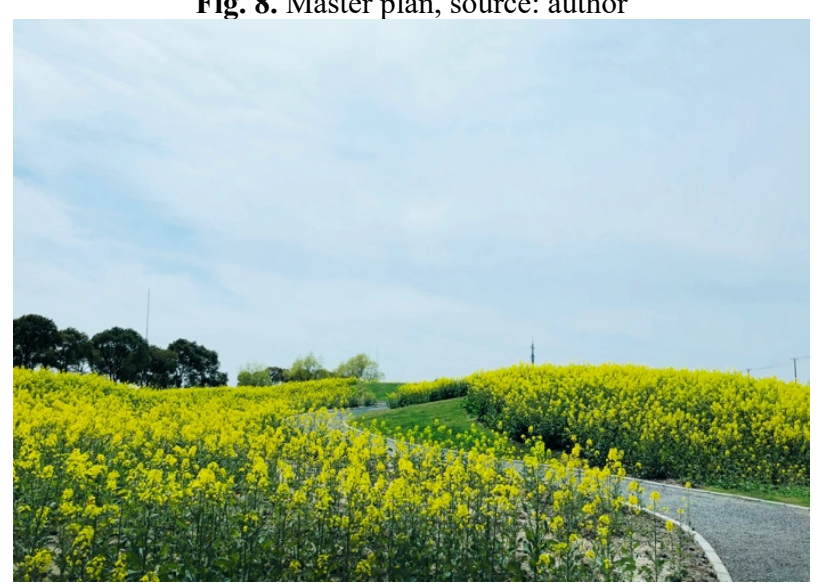

Fig. 9. Photo, source: author

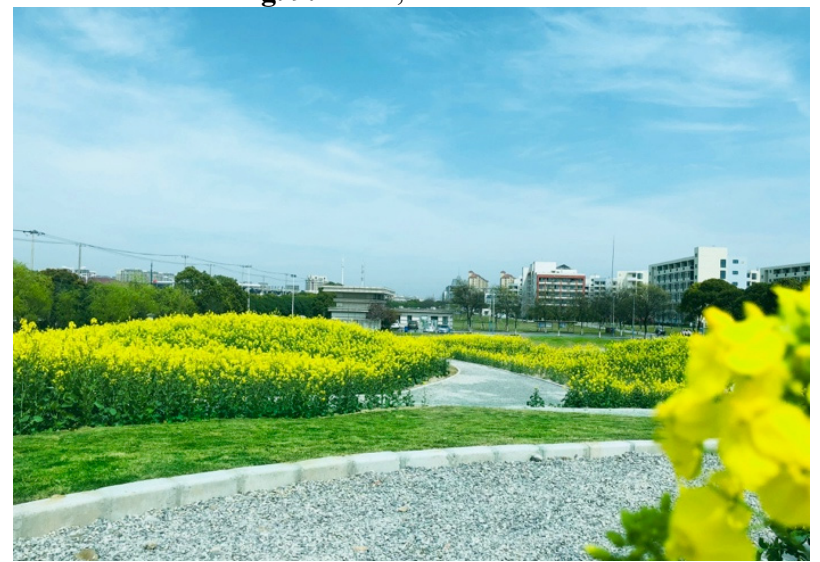

Fig. 10. Photo, source: author

\section{Conclusions}

The cultural construction of the new campus has a long way to go, and the integration of regional characteristics is an important way to create campus features. For the campus that has already been built, it can be slowly upgraded by means of landscape implantation. For the planned campus, it is hoped that the campus culture will be integrated as an important part at the beginning of the design, and local characteristics will be fully explored, and not only be inherit but also carried out with innovation.

\section{Acknowledgement}

Sponsored by Shanghai Chenguang Project (16CG72)

\section{References}

1. Ministry of Education of the People's Republic of China, 2017 National Statistical Report on Education Development, 23-24 (2018)

2. Department of Education, Department of Ideological and Political Education, Theory and Practice of Campus Culture Construction in Colleges and Universities, 67 (2011)

3. Office of the Principal, Introduction to the Campus of East China University of Science and Technology. ECUST,https://www.ecust.edu.cn/67/list.htm.(2018)

4. Shanghai Fengxian District Government. 2017 Statistical Report on National Economic and Social Development of Fengxian District,124（2018）

5. Agricultural Products Processing Bureau of the Ministry of Agriculture, LABV, 07,66-71(2016) 